\title{
Retroversion of the esophagoscope to find a bronchoesophageal fistula inside an esophageal diverticulum in a patient with achalasia
}

\section{Case description}

A 28-year-old male patient with a childhood history of pulmonary tuberculosis who had undergone pneumatic balloon dilatation 2 years previously for achalasia ( $\triangleright$ Fig. 1) presented with a 1-year history of cough during meals. Esophagoscopy performed for suspicion of tracheoesophageal fistula showed esophageal dilation and a small diverticulum in the midesophagus ( $\mathbf{F i g . 2}$ ). Bronchoscopy showed a fistulous opening in the left main bronchus, for which a fully-covered metal stent was placed inside the bronchus (\$ Fig.3). Four months later, esophagoscopy was performed to confirm fistula closure. Because forwardviewing esophagoscopy did not reveal a fistulous opening, a careful retroversion

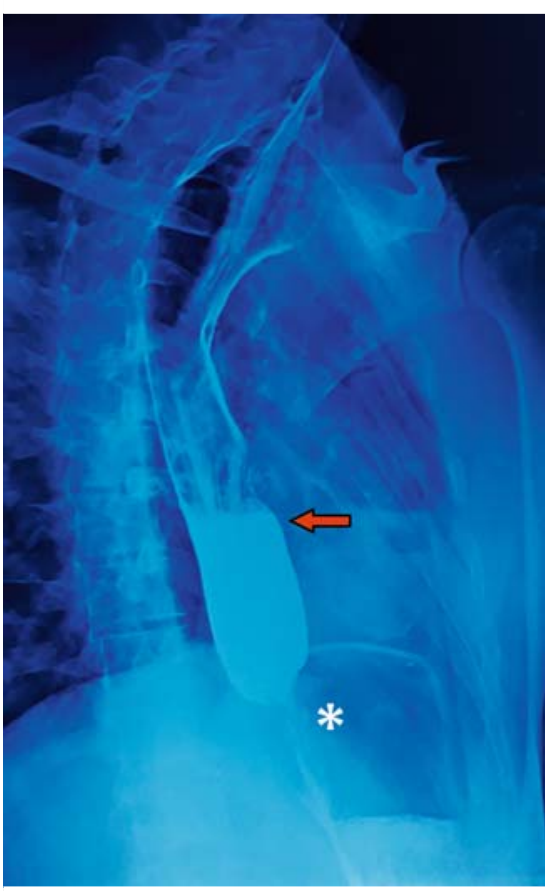

- Fig. 1 Lateral view of barium esophagogram depicting dilated esophagus with pooling of barium (red arrow) and narrowed gastroesophageal junction (asterisk).

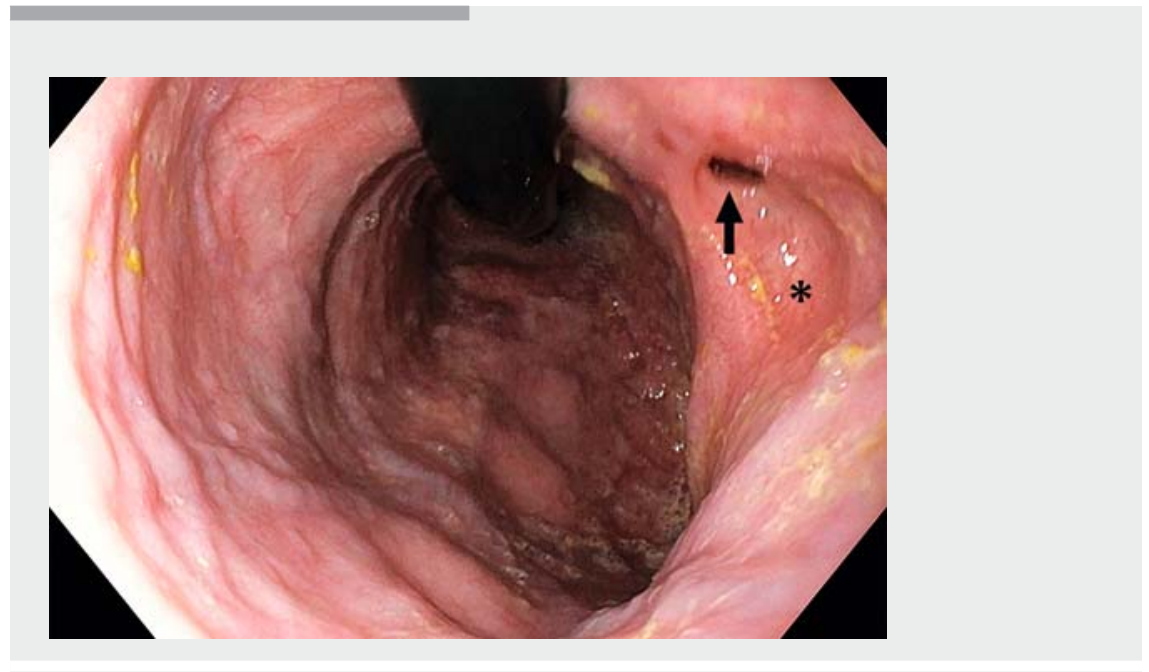

Video 1 Demonstration of retroversion technique for localizing bronchoesophageal fistula in a patient with achalasia.

and slow withdrawal of the esophagoscope was performed (\$Video $\mathbf{1}$ ). It revealed a fistulous opening at the apex of the diverticulum in the mid-esophagus (-Fig.4).

Bronchoesophageal fistula is rare condition and can be congenital or acquired [1]. Usually, bronchoesophageal fistula is visualized on forward-viewing esophagoscopy. But if a fistulous opening is inside the esophageal diverticulum, it is

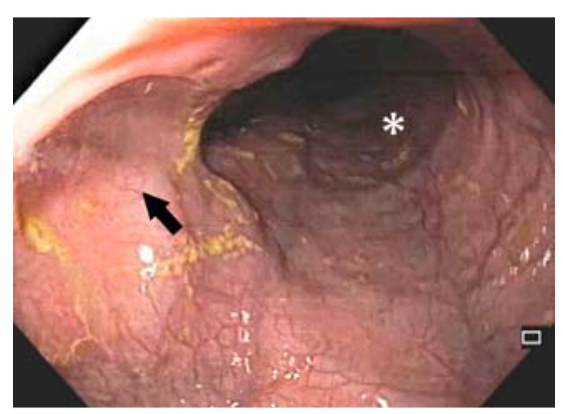

- Fig. 2 Endoscopic image showing dilated esophagus (asterisk) and a midesophgeal diverticulum (black arrow) and non-visualization of the opening of the bronchoesophageal fistula. difficult to appreciate it on forwardviewing esophagoscopy, and retroversion of the endoscope can be tried in the dilated esophagus. This case is unique in many aspects in that: 1) bronchoesophageal fistula is rare inside an esophageal diverticula [2]; 2) association with achalasia is rare [3]; and 3) visualization was possible on retroversion of the

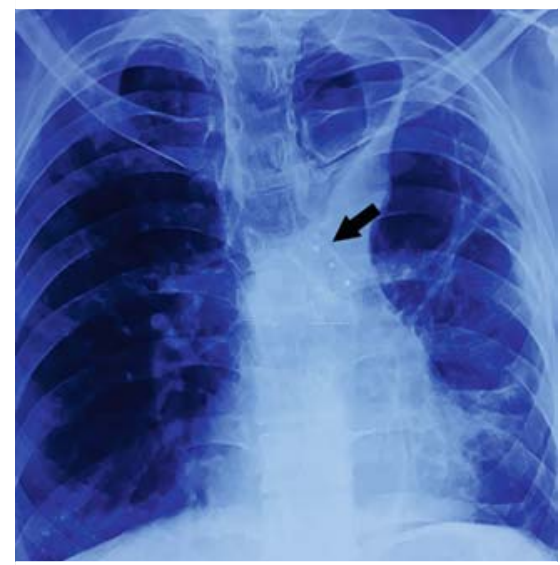

- Fig. 3 Chest $x$-ray showing fibrosis in the left lung with a metal stent inside the left main bronchus (arrow). 


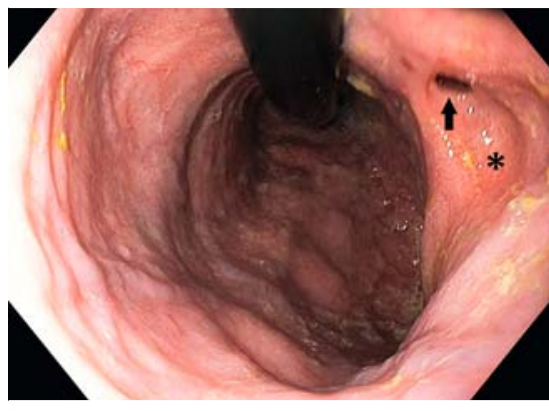

- Fig. 4 Endoscopic image in retroversion depicting a small opening (arrow) at the apex of the diverticulum (asterisk) and dilated esophagus. Esophagoscope is visible at 12 o'clock position.

esophagoscope. Caution should be exercised, however, while performing retroversion during esophageal endoscopic examination, as the limited space may lead to complications.
Competing interests

The authors declare that they have no conflict of interest.

The authors

Deepak Gunjan, Ashish Agarwal, Soumya Jagannath, Kanav Kaushal

Department of Gastroenterology and Human Nutrition Unit, All India Institute of Medical Sciences, New Delhi, India

Corresponding author

Deepak Gunjan, MD, DM, Assistant Professor

Department of Gastroenterology and Human Nutrition Unit, All India Institute of Medical Sciences, Ansari Nagar, New Delhi, India

Fax: +911126588663

drdg_01@rediffmail.com
References

[1] Barbara DW, Broski SM, Blackmon S. Bronchoesophageal fistula. Can J Anaesth 2017; 64: 1267-1268

[2] López A, Rodríguez P, Santana N et al. Esophagobronchial fistula caused by traction esophageal diverticulum. Eur J Cardiothorac Surg 2003; 23: 128-130

[3] Zhu J, Ni Y, Lu Q et al. Benign esophago-pulmonary fistula complicating achalasia: case report and literature review. J Thorac Dis 2015; 7: E92-E96

\section{Bibliography}

DOI http://dx.doi.org/10.1055/a-1190-7854

Endoscopy International Open 2020; 08: E1042E1043

(c) Georg Thieme Verlag KG

Stuttgart · New York

eISSN 2196-9736

다)(i) $\odot$ 